\title{
Temporal and spatial variations in TEC using simultaneous measurements from the Indian GPS network of receivers during the low solar activity period of 2004-2005
}

\author{
P. V. S. Rama Rao, S. Gopi Krishna, K. Niranjan, and D. S. V. V. D. Prasad \\ Space Physics Laboratory, Department of Physics, Andhra University, Visakhapatnam 530003, India
}

Received: 28 April 2006 - Revised: 14 September 2006 - Accepted: 26 October 2006 - Published: 21 December 2006

\begin{abstract}
With the recent increase in the satellite-based navigation applications, the ionospheric total electron content (TEC) and the L-band scintillation measurements have gained significant importance. In this paper we present the temporal and spatial variations in TEC derived from the simultaneous and continuous measurements made, for the first time, using the Indian GPS network of 18 receivers located from the equator to the northern crest of the equatorial ionization anomaly (EIA) region and beyond, covering a geomagnetic latitude range of $1^{\circ} \mathrm{S}$ to $24^{\circ} \mathrm{N}$, using a 16-month period of data for the low sunspot activity (LSSA) years of March 2004 to June 2005.

The diurnal variation in TEC at the EIA region shows its steep increase and reaches its maximum value between 13:00 and 16:00 LT, while at the equator the peak is broad and occurs around 16:00 LT. A short-lived day minimum occurs between 05:00 to 06:00 LT at all the stations from the equator to the EIA crest region. Beyond the crest region the day maximum values decrease with the increase in latitude, while the day minimum in TEC is flat during most of the nighttime hours, i.e. from 22:00 to 06:00 LT, a feature similar to that observed in the mid-latitudes. Further, the diurnal variation in TEC show a minimum to maximum variation of about 5 to $50 \mathrm{TEC}$ units, respectively, at the equator and about 5 to 90 TEC units at the EIA crest region, which correspond to range delay variations of about 1 to $8 \mathrm{~m}$ at the equator to about 1 to $15 \mathrm{~m}$ at the crest region, at the GPS L1 frequency of $1.575 \mathrm{GHz}$. The day-to-day variability is also significant at all the stations, particularly during the daytime hours, with maximum variations at the EIA crest regions. Further, similar variations are also noticed in the corresponding equatorial electrojet (EEJ) strength, which is known to be one of the major contributors for the observed day-to-day variability in TEC.
\end{abstract}

Correspondence to: P. V. S. Rama Rao

(palurirao@yahoo.com)
The seasonal variation in TEC maximizes during the equinox months followed by winter and is minimum during the summer months, a feature similar to that observed in the integrated equatorial electrojet (IEEJ) strength for the corresponding seasons. In the Indian sector, the EIA crest is found to occur in the latitude zone of $15^{\circ}$ to $25^{\circ} \mathrm{N}$ geographic latitudes $\left(5^{\circ}\right.$ to $15^{\circ} \mathrm{N}$ geomagnetic latitudes). The EIA also maximizes during equinoxes followed by winter and is not significant in the summer months in the LSSA period, 20042005. These studies also reveal that both the location of the EIA crest and its peak value in TEC are linearly related to the IEEJ strength and increase with the increase in IEEJ.

Keywords. Ionosphere (Equatorial ionosphere; Electric fields and currents) - Radio science (Ionospheric propagation)

\section{Introduction}

In recent years, with the increasing demand on the transionospheric communication systems used in the navigation of space-borne vehicles, such as satellites, aircraft, as well as surface transportation systems, the measurement of the true value of the Total Electron Content (TEC) of the ionosphere has become important for making appropriate range corrections, as well as in accounting for errors introduced in the range delays owing to the effects of space weather related events, such as geomagnetic storms and scintillations due to ionospheric irregularities.

Broad features in the temporal and spatial behaviour of the total electron content of the ionosphere in the global perspective is known to a great extent (Kane, 1980). The ionization in the equatorial and polar regions is known to be high compared to relatively moderate levels of electron content in the mid-latitude ionospheric regions. Also, the changes in the temporal and spatial features of TEC at the mid latitudes are

Published by Copernicus GmbH on behalf of the European Geosciences Union. 
relatively small compared to the equatorial and low-latitude regions (Davies, 1980), where these changes are significant, owing to the dynamical behaviour of the ionosphere because of the various processes associated with the phenomena of equatorial ionization anomaly (EIA) and equatorial spread-F (ESF) irregularities in these regions.

During the past three decades, with the availability of the orbiting satellites, such as BE-B and BE-C, INTASAT and the geostationary satellites, such as ATS-6, ETS-2 and SIRIO, several researchers have made significant contributions by making individual measurements of TEC from various locations in India (Rastogi and Sharma, 1971; Das Gupta and Basu, 1973; Rastogi et al., 1975; Rama Rao et al., 1977; Davies et al., 1979). The results of these studies have revealed the broad characteristic features in the morphological behaviour of the total electron content in the Indian sector. However, there were no coordinated, simultaneous or continuous measurements of TEC from all the latitude zones of the Indian region, except for some measurements made with the ATS-6 satellite when the satellite was housed at $35^{\circ} \mathrm{E}$ longitude during $1975-1976$ for the SITE (Satellite Television Experiment) Experiment in India, where there were several data gaps during the late evening hours due to switching off of the beacons in order to save power for the SITE programmes. Now, with the launching of the GAGAN project in India, simultaneous and continuous measurements are being made for the past 3 years from the network of 18 dual frequency GPS receivers installed at $\left(5^{\circ} \times 5^{\circ}\right.$ grid spacing $)$ different latitude and longitude regions in the country (http://www.aiaa.org/indiaus2004/ Sat-navigation.pdf and http://www.mycoordinates.org/ gagan-update-arjunsingh-mar-06.php). This network of GPS receivers has provided a unique opportunity for a continuous monitoring of the behaviour of TEC in the entire Indian zone.

\section{TEC measurement using Global Positioning System (GPS)}

All modern TEC measuring techniques rely on the observation of signal phase differences or on pulse travel time measurements, based on geostationary and orbiting satellite signals. A standard way of measuring TEC is to use a groundbased receiver capable of processing signals from satellites in geostationary orbits and polar orbiting satellites. In recent times, the Global Positioning System (GPS, or NAVSTAR), a satellite-based navigation system is increasingly being used for all-weather precision navigation over land, sea and in air, by both military and civilian users. In principle, it should be possible to obtain offset free TEC data from GPS by measuring the differential group delay instead of the phase shift (or phase delay).

The dual frequency GPS receiver system provides a means of monitoring the effect of the ionosphere on GPS signals. It is particularly intended to measure the integrated ionization content between satellite and receiver, and is also capable of detecting scintillations at L-band frequencies. Operation at the L1 and L2 frequencies simultaneously permits measurement of the relative phase delay between the two signals, producing an unambiguous determination of the slant TEC, or the total number of electrons in a column of cross-sectional area of one-square metre along the signal path between the satellite and the receiver. For a single frequency GPS receiver, the ionospheric delay cannot be determined uniquely, but must be estimated from a model, with an uncertain effect on the final navigation solution. Thus, TEC is of significant concern for users of single frequency GPS receivers and particularly for those located under the equatorial ionization anomaly region, where the reliability of the GPS provided model is in question.

The GPS navigation system comprises of three distinct "segments" (Sonnenberg, 1988; Ackroyd and Lorimer, 1990), of which the first one is the space segment that consists of a constellation of 24 satellites transmitting coded signals downward to receivers on the Earth's surface. The second is the control segment, which includes ground stations used for monitoring satellites and sending signals upward for the engineering control of each satellite and its transmitted codes and waveforms. And the third one is the user segment which includes everyone with a GPS receiver who is making use of the transmitted signals. Satellites are equispaced around each of the six circular orbital planes inclined at $55^{\circ}$ to the plane of the Earth's equator. The orbital altitude is $\approx 20200 \mathrm{~km}$, with an orbital period of $12 \mathrm{~h}$. The geometry in the location of the satellite constellation is such that, from any point on the Earth's surface with a reasonably unobstructed horizon, signals from at least four satellites will always be available in the line of sight and it will therefore be possible to solve the four unknowns of the receiver, namely latitude, longitude, altitude and the combined satellite/receiver timing error.

Each satellite continuously transmits frequencies in the L-band of the microwave spectrum, at $\mathrm{L} 1=1.57542 \mathrm{GHz}$ and $\mathrm{L} 2=1.2276 \mathrm{GHz}$, respectively. The $\mathrm{L} 1$ and $\mathrm{L} 2$ carriers are phase coherent, both being derived from a common 10.23 MHz oscillator. Both the frequencies are modulated by a common binary code called the precision code (P-code), the use of which allows the delay error introduced by the ionospheric refraction to be eliminated from the final position determination, permitting the determination of the total electron content (TEC) along the signal path. This encrypted $\mathrm{P}$-code is unavailable to the general user. The L1 frequency is also modulated by the coarse acquisition code (C/A code) and is used by single frequency receivers. The GPS receiver calculates its position by selecting the optimum configuration of four satellites and by finding its range with respect to each satellite. The range is determined from the delay in the time taken for the signal to travel from each of the satellites to the receiver, as measured by the difference between the satellite 
transmit time, which is known, and the signal reception time which is measured by autocorrelation. However, this difference does not take into account any error in the receiver's clock relative to the satellite's clock and therefore the range is only approximate and is therefore called a pseudorange.

The ionosphere has a refractive index at radio frequencies, which is different from unity and can affect GPS signals in a number of ways as they pass from satellite to ground (Coco, 1991; Wanninger, 1993; Klobuchar, 1996). One of the significant effects is that the GPS signal traversing the ionosphere undergoes an additional delay proportional to the total number of electrons in the cross-section volume measured in TEC units. The dual frequency GPS receivers use two frequencies, L1 (1575.42 MHz) and L2 (1227.60 MHz), to compensate for the ionospheric delay, which remove these effects, at least to a first order approximation, taking advantage of the dispersive nature of the ionosphere, where the refractive index is a function of frequency. The ionospheric time delay at the L1 carrier frequency of $f_{1}$ as given by Klobuchar (1996) is

$t_{1}=40.3 \times\left(\mathrm{TEC} / C \cdot f_{1}^{2}\right)$,

where $C$ is the speed of light in free space. A dual frequency $\left(f_{1}\right.$ and $\left.f_{2}\right)$ receiver measures the difference in time delay between the two frequencies, $\Delta t=t_{2}-t_{1}$, given by

$\Delta t=(40.3 / C) \times \frac{\mathrm{TEC}}{\left[\left(1 / f_{2}^{2}\right)-\left(1 / f_{1}^{2}\right)\right]}$.

Thus, the time delay $(\Delta t)$ measured between the L1 and L2 frequencies is used to calculate the TEC along the ray path. The calculation of TEC by the above method, using pseudorange data alone, can produce a noisy result, while the differential carrier phase gives a precise measure of the relative TEC variations, because the actual number of cycles of phase is not known. Absolute TEC cannot be obtained unless pseudorange is also used. Therefore, use of the pseudorange gives the absolute scale for TEC while the differential phase increases measurement accuracy. Thus, the GPS data provides an efficient way to estimate TEC values with greater spatial and temporal coverage (Davies and Hartmann, 1997; Hocke and Pavelyev, 2001). Since the frequencies that are used in the GPS system are sufficiently high, the signals are minimally affected by the ionospheric absorption and the Earth's magnetic field, both in the short-term, as well as in the longterm changes in the ionospheric structure.

In the Indian low-latitude sector several isolated TEC measurements were made during the past three to four decades, using data from a number of orbiting, as well as geostationary satellite signals, the studies of which led to a broad understanding of the behaviour of the equatorial and low-latitude ionosphere. However, in the recent past, with the availability of simultaneous data of TEC from the Indian GPS network of receivers, it has become possible to make a simultaneous and systematic study on the behaviour of the ionosphere from a large and continuous database, for use in the navigational application purposes over the Indian region.

The application of GPS has increased enormously in Navigation, surveillance, etc. and recently, in the aircraft's landing category-I precision approach, by augmenting the GPS with a Space Based Augmentation System (SBAS) signal. Thus, the TEC measurements have gained importance in estimating the range delays involved in the GPS-based navigation.

In this paper we report the results obtained by the studies carried out using a 16-month TEC data from March 2004 to June 2005, recorded by the Indian GPS network of receivers.

\section{Data and method of analysis}

In the Indian sector, which encompasses the equatorial and low-latitude regions, the Indian Space Research Organization (ISRO) and the Airport Authority of India (AAI) have jointly launched a project called GPS Aided Geo Augmented Navigation (GAGAN). This is similar to the Wide Area Augmentation System (WAAS) in operation in the United States. A total of 18 identical, dual-frequency GPS receivers are installed at different locations in the length and breath of the country, all the way from the magnetic equator to the equatorial ionization anomaly crest region and beyond, with a view to study the temporal and spatial behavior of the Indian ionosphere in greater detail by using the continuous measurement of the TEC and scintillation data ( $S_{4}$ index) acquired at a grid spacing of about $5^{\circ} \times 5^{\circ}$ in latitude and longitude. In Fig. 1, the locations of the GPS receiver stations installed in the Indian region are shown, where the longitudinal coverage of these stations varies from $72^{\circ} \mathrm{E}$ to $92^{\circ} \mathrm{E}$, and the geographic latitudinal coverage varies from $8^{\circ}$ to $32^{\circ} \mathrm{N}$ or in a range of $1^{\circ} \mathrm{S}$ to $23^{\circ} \mathrm{N}$ geomagnetic latitude. The GSV 4004 Ionospheric Scintillation Monitor receivers (ISMs) collect the TEC and scintillation data (Van Dierendonck et al., 1996). Each ISM can track up to 11 GPS C/A-code signals at the L1-frequency of $1.575 \mathrm{GHz}$. The data is collected at oneminute intervals from all the stations, which do not include the 50-Hz sampled raw data, but the reduced TEC and $S_{4}$ index and other parameters are included. The $S_{4}$ index is calculated from the normalized standard deviation of raw signal intensity $\left(S_{4 T}\right)$ and that of ambient noise $\left(S_{4, \mathrm{NO}}\right)$, using the relation $S_{4}=\operatorname{Sqrt}\left[\left(S_{4 T}\right)^{2}-\left(S_{4, \mathrm{NO}}\right)^{2}\right]$ (Rama Rao et al., 2006). In the present study, the (slant) TEC data, recorded at all the 18 different locations during the sixteen-month period, from March 2004 to June 2005, is used in this analysis.

Here, the slant TEC measurements made are the sum of the real slant TEC, the GPS satellite differential delay $b_{S}$ (satellite bias) and the receiver differential delay, $b_{R}$ (receiver bias). Therefore, the vertical TEC can be expressed as

$\mathrm{VTEC}=\left(\mathrm{STEC}-\left[b_{R}+b_{S}\right]\right) / S(E)$, 


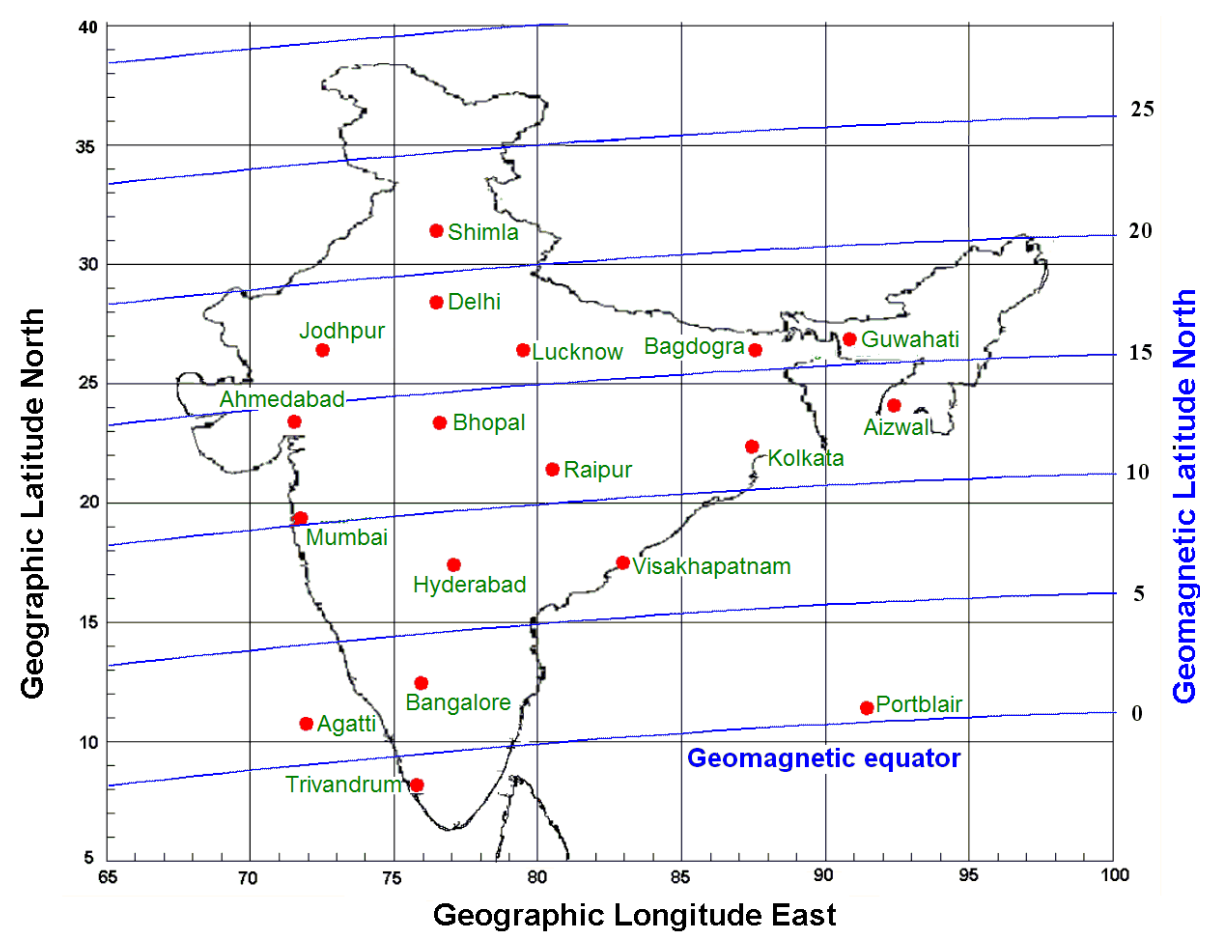

Fig. 1. Locations of GPS Receiver stations in India.

where "STEC" is the slant TEC measured, $E$ is the elevation angle of the satellite in degrees, $S(E)$ is the obliquity factor with zenith angle $z$ at the Ionospheric Pierce Point (IPP) and "VTEC" is the vertical TEC at the IPP. The obliquity factor, $S(E)$ (or the mapping function) is defined as (Mannucci et al., 1993; Langley et al., 2002)

$S(E)=\frac{1}{\cos (z)}=\left\{1-\left(\frac{R_{E} \times \cos (E)}{R_{E}+h_{S}}\right)^{2}\right\}^{-0.5}$,

where $R_{E}$ is the mean radius of the Earth in $\mathrm{km}, h_{S}$ is the ionosphere (effective) height above the Earth's surface, $z$ is the zenith angle and $E$ is the elevation angle in degrees. The vertical TEC (VTEC) thus measured is used in deriving the results presented in the following sections of this paper.

\section{Diurnal variation of total electron content of the iono- sphere in the Indian sector}

The slant TEC measured at every 1-min interval from the data of the GPS receivers are converted to vertical TEC for the study of temporal and spatial variations of TEC in the Indian region. In Figs. 2a, b, c and d, the diurnal variation plots of TEC are presented for a typical quiet day (2 April 2004), derived from all the visible satellites from the four stations representing the four different latitude zones, ranging from the equator to the ionization anomaly crest region and beyond, namely Trivandrum $\left(8.5^{\circ} \mathrm{N}, 0^{\circ}\right.$ geomagnetic), an equatorial station, Waltair $\left(17.7^{\circ} \mathrm{N}\right)$, a sub-tropical station, Kolkata $\left(22.6^{\circ} \mathrm{N}\right)$, a station at the anomaly crest region and Delhi $\left(28.6^{\circ} \mathrm{N}\right)$, a station located beyond the anomaly crest region. It may be seen from Figs. 2a, b, c, and d that there is a considerable spread in the diurnal variation of TEC derived from different satellite passes, which is visible at each of these four different stations. However, the spread in TEC at the equatorial station Trivandrum is minimum, whereas at Kolkata, the spread in TEC is maximum, indicating the effect due to the presence of strong latitudinal gradients at the anomaly crest region compared to those at the equatorial station. Stations Waltair and Delhi show the spread of VTEC values as per the ionization distribution around their latitudes. In all these plots the diurnal variation shows a sharp and short-lived day minimum ( $\approx 5 \mathrm{TECU})$ in TEC occurring around 05:00 to 06:00 IST (LT). A delayed (16 to $17 \mathrm{~h} \mathrm{IST)}$ day maximum (55 TEC units) in TEC occurs at Trivandrum, whereas at Kolkata a large (95 TEC units) and early (12:00 to 14:00 IST) day maximum in TEC occurs. The corresponding diurnal variation in the range corrections to be made on this particular day at the L1 frequency of $1.575 \mathrm{GHz}$ vary from 1 to $10 \mathrm{~m}$ at the equatorial station and from 1 to $16 \mathrm{~m}$ at the anomaly crest station, indicating that different regions in India need different range corrections to be made in the navigational applications.

Figure $3 \mathrm{a}$ shows a plot of the diurnal variation of TEC over a low-latitude station Waltair $\left(17.7^{\circ} \mathrm{N}, 83.3^{\circ} \mathrm{E}\right)$ derived from all the visible satellite passes, on a typical quiet day, 


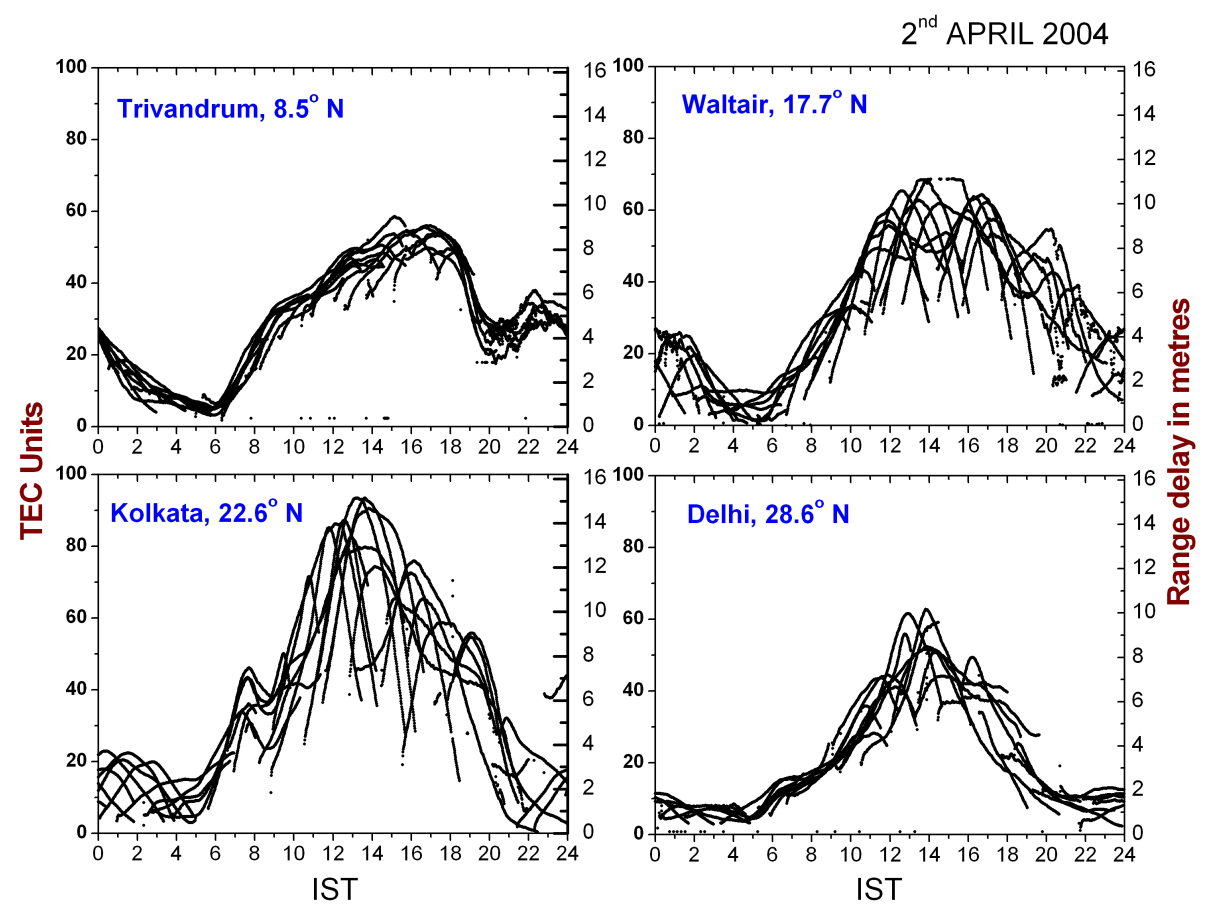

Fig. 2. The diurnal variation of vertical TEC/range delays measured using GPS receivers from four different stations near the equator (Trivandrum), the low latitude (Waltair), the anomaly crest region (Kolkata) and beyond the crest region (Delhi).

30 March 2004 (a quiet day as per the classification given in the webpage http://swdcwww.kugi.kyoto-u.ac.jp/qddays/ index.html). It is observed from this figure that the diurnal variation of the TEC measured from different passes varies (spread) significantly, owing to the spatial and temporal variations in TEC, because these values are derived from different GPS satellite passes that are spread in different parts of the sky and at different local times over Waltair region. After making a number of trial runs, to obtain a good average diurnal variation plot of TEC, an elevation mask angle of $50^{\circ}$ is arrived at to be ideally suited to eliminate the low elevation angle effects, due to multipath and tropo-scatter, due to water vapor on the measured TEC values. In Fig. $3 b$ is shown the diurnal variation of the vertical TEC, thus derived from Waltair for passes with elevation angles $>50^{\circ}$. This TEC data is then subjected to a two-sigma $(2 \sigma)$ iteration, and the resulting values represent the average diurnal variation of TEC on that day over Waltair. A similar procedure is followed in computing the diurnal variations of TEC over all the other stations in the entire network.

The vertical TEC values of all the visible satellite passes with elevation angles $>50^{\circ}$ seen from each of the 18 stations is thus computed using the measured slant TEC data as described above. The diurnal variation plots for each of the days of the 16-month period from March 2004 to June 2005 are prepared for a detailed study of temporal and spatial variations of TEC over the Indian region, using a software developed in house ( $\mathrm{VC}++)$ for this purpose. The red curves in
Figs. 3a and $b$, show the iterated average plots of the vertical TEC thus derived using this software. The biases of the receiver are determined by observing the day minimum TEC values from the diurnal variation plots of the respective stations and then by subjecting them to a 2-sigma iterated average of all satellite passes at each of the stations. This process is also carried out automatically by the above software.

For making an appropriate and systematic study on the latitudinal behavior of the diurnal variation of TEC, in the Indian sector, the GPS-TEC data from a total of seven different locations, namely Trivandrum $\left(8.47^{\circ} \mathrm{N}, 76.91^{\circ} \mathrm{E}\right)$, Bangalore $\left(12.95^{\circ} \mathrm{N}, 77.68^{\circ} \mathrm{E}\right)$, Hyderabad $\left(17.44^{\circ}, 78.47^{\circ} \mathrm{E}\right)$, Raipur $\left(21.18^{\circ} \mathrm{N}, 81.74^{\circ} \mathrm{E}\right)$, Bhopal $\left(23.28^{\circ} \mathrm{N}, 77.34^{\circ} \mathrm{E}\right)$, Delhi $\left(28.58^{\circ} \mathrm{N}, 77.21^{\circ} \mathrm{E}\right)$ and Shimla $\left(31.09^{\circ} \mathrm{N}, 77.07^{\circ} \mathrm{E}\right)$, situated approximately along the common meridian of $77^{\circ} \mathrm{E}$ longitude, extending all the way from the magnetic equator (Trivandrum) to the equatorial ionization anomaly crest region (Raipur and Bhopal) and beyond (Delhi and Shimla), are considered. The vertical TEC derived from the measured GPS slant TEC (as described in the previous section) has been computed for all the quiet days from the seven identified stations for three typical months, namely March 2004, December 2004 and June 2004 representing the equinox, winter and summer seasons, respectively. Mass plots of the diurnal variations of TEC for each of these three months are presented in Figs. 4, 5 and 6, respectively, along with the corresponding diurnal variations of the equatorial electrojet strengths derived from the conventional method of 

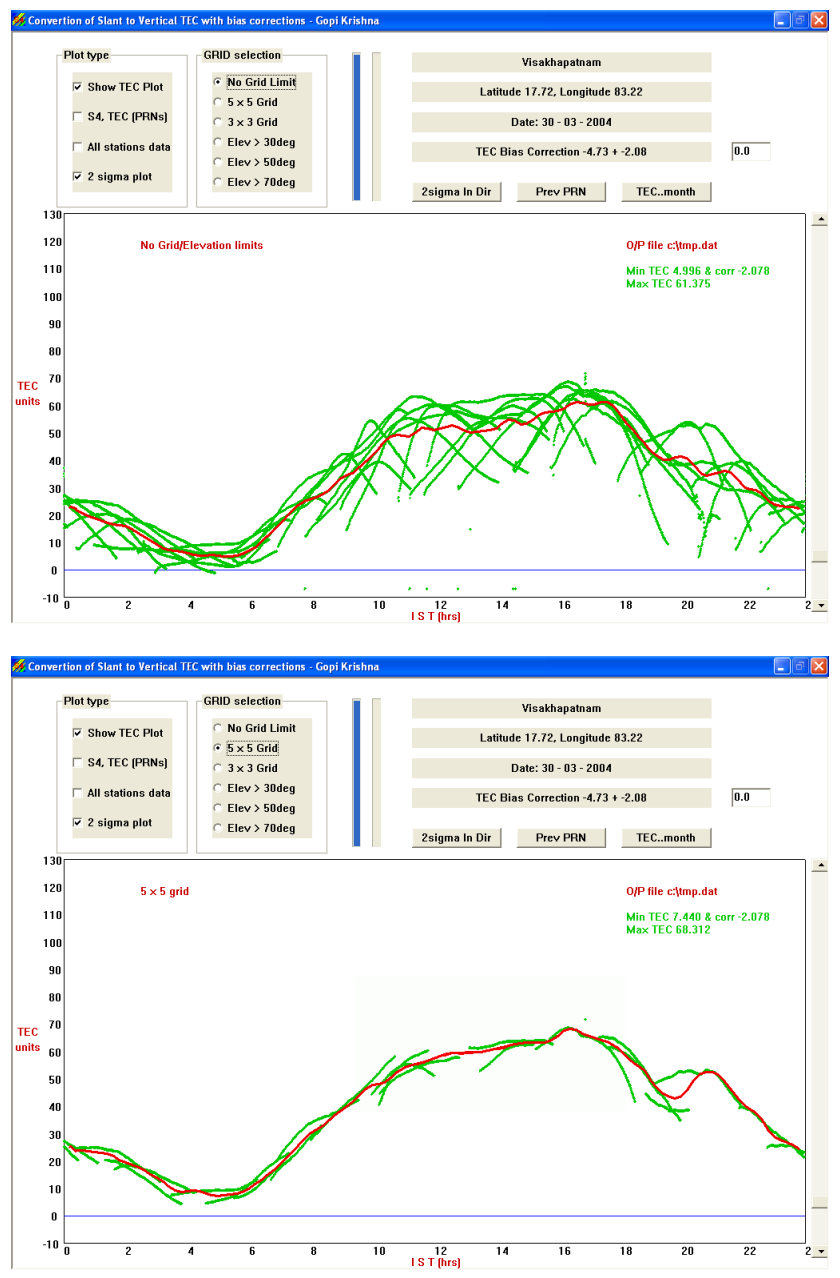

Fig. 3. Diurnal variation of vertical TEC with time at Visakhapatnam for a typical day of 30 March 2004, subjected to a two-sigma iteration (red line) and automatic calculation of receiver bias using the software developed; (a) without any elevation mask angle and (b) with an elevation mask angle of $50^{\circ} \approx 5^{\circ} \times 5^{\circ}$ grid.

subtracting the horizontal components of the Earth's magnetic field at the equator, Trivandrum $\left(8.47^{\circ} \mathrm{N}\right)$, from that at Alibagh $\left(18.5^{\circ} \mathrm{N}\right)$, a station lying outside the equatorial electrojet in the Indian region (Chandra and Rastogi, 1974). In general, it may be noticed from these figures that the diurnal maxima of TEC are highest during the equinoxial month of March followed by the winter month of December. During the summer month of June the diurnal maxima are minimum. In the equinoxial month of March (Fig. 4) it may also be noticed that the diurnal minimum in TEC occurs around 05:00 to 06:00 LT in the equatorial ionization anomaly zone, i.e. from Trivandrum to Raipur, whereas beyond the anomaly crest region, i.e. at Delhi and Shimla, the day minimum is flat during most of the nighttime hours (22:00 to 06:00 LT), a feature which is similar to that at mid-latitudes. Secondly, the early morning increase in TEC is relatively fast at Trivan- drum, Hyderabad and Raipur compared to that at Delhi and Shimla. At the equatorial station, Trivandrum, the day maximum is relatively broad and is of longer duration compared to that at the anomaly crest regions, Raipur and Bhopal. In particular, during the month of March the late afternoon decrease in TEC is equally steeper with occasional post sunset enhancements around the anomaly crest region encompassing stations like Hyderabad, Raipur and Bhopal. During the equinoxial month of March there is a nighttime maintenance of the ionosphere with an average TEC value of about 15 to 20 TEC units in the diurnal variations at stations up to the anomaly crest region, even during this low sunspot activity period (2004-2005). During the winter month of December similar features are also seen but with reduced intensity, whereas during the summer month of June, the nighttime values of TEC are almost constant at the minimum level during most of the nighttime hours. In all these figures (Figs. 4, 5 and 6), one very important feature that is noticeable is the day-to-day randomness in the variation of TEC, particularly during the mid-day to pre-dawn hours, which is of serious concern in forecasting, as well as in navigation.

This randomness in the day-to-day variation in TEC (Kane, 1980; Mendillo et al., 1980; Modi and Iyer, 1989) may be attributed to the changes in the activity of the Sun itself and to the associated changes in the intensity of the incoming radiations, and the zenith angle $(\chi)$ at which they impinge on the Earth's atmosphere, in addition to the changes which take place in the Earth's magnetic field and the equatorial electrojet (EEJ) strength, added to the effects due to the dynamics of the neutral winds. Further, from Figs. 4, 5 and 6 , it may also be noticed that the day-to-day variability in the EEJ strength is equally significant, similar to that of the TEC during all three months considered. Added to all these, the plasma flow associated with the EIA may also play a significant role in the day-to-day variability of the observed diurnal variations in TEC at different stations in the Indian region. Therefore, forecasting TEC for the Indian ionosphere at any particular latitude, at any given point of time, is a difficult task, and the models used earlier, such as IRI, SLIM, PRISM and SUPIM from different groups worldwide did not give satisfactory results that agree with the measurements made in the equatorial and low-latitude regions. Therefore, there is an absolute need to develop a model which is suitable to the Indian equatorial and anomaly crest regions, taking into account the various mechanisms and parameters which play a major role in introducing randomness in the diurnal variation of TEC in the Indian region.

\section{Seasonal variation in TEC}

Following the procedure described in Sect. 4 the data for the diurnal variation of the 16-month period, i.e. from March 2004 to June 2005, is considered for computation of the diurnal variation of TEC during all the quite days. The contour 


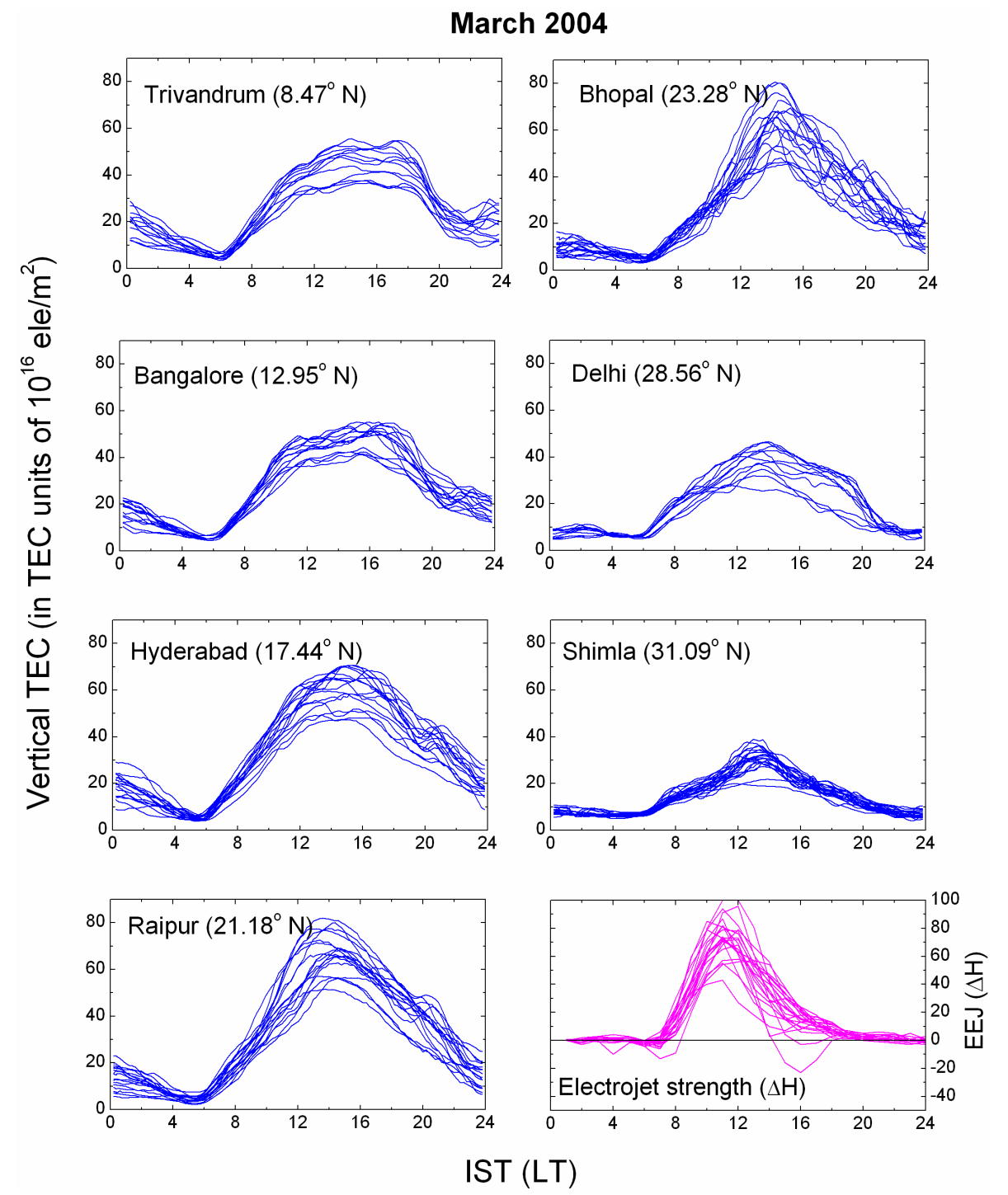

Fig. 4. Mass plots of the diurnal variation of TEC measured at seven locations situated along a common meridian of $77^{\circ} \mathrm{E}$ longitude for the quiet days in the equinoxial month of March 2004, presented along with the diurnal variations of the corresponding electrojet strength (EEJ) variations.

diagrams of the average diurnal variation of the electron content for each of the 16 months at each of the local hours at Trivandrum, Hyderabad, Raipur and Delhi, representing the four different latitude zones in the Indian sector, are presented in Figs. 7a, b, c and d, respectively. It may be seen from these figures that the diurnal maximum in TEC occurs approximately between 12:00 to 16:00 LT, particularly at Hyderabad, Raipur and Delhi, whereas at the equatorial station Trivandrum, the occurrence of the diurnal maximum is slightly delayed and occurs around 16:00 LT. The highest day maximum TEC ( $\approx 60$ TEC units) occurs at Raipur and Hyderabad, peaking around the equinoxial months of September, October and the winter month of November, while at Delhi a reduced diurnal maximum $(\approx 40$ TEC units) occurs during the same months. At all these four stations the equinoxial maxima showing the semidiurnal variation in TEC is strongly evident, indicating the role played by the solar zenith angle variation in the changes produced by the level of production of ionization, added to the role played by the equatorial ionization anomaly and the strength of the equatorial electrojet, which also maximizes during the equinoxial months.

\section{Latitudinal variation of the total electron content in the Indian sector}

An interesting feature in the geographic location of India is that the magnetic equator passes through the bottomside tip 


\section{December 2004}
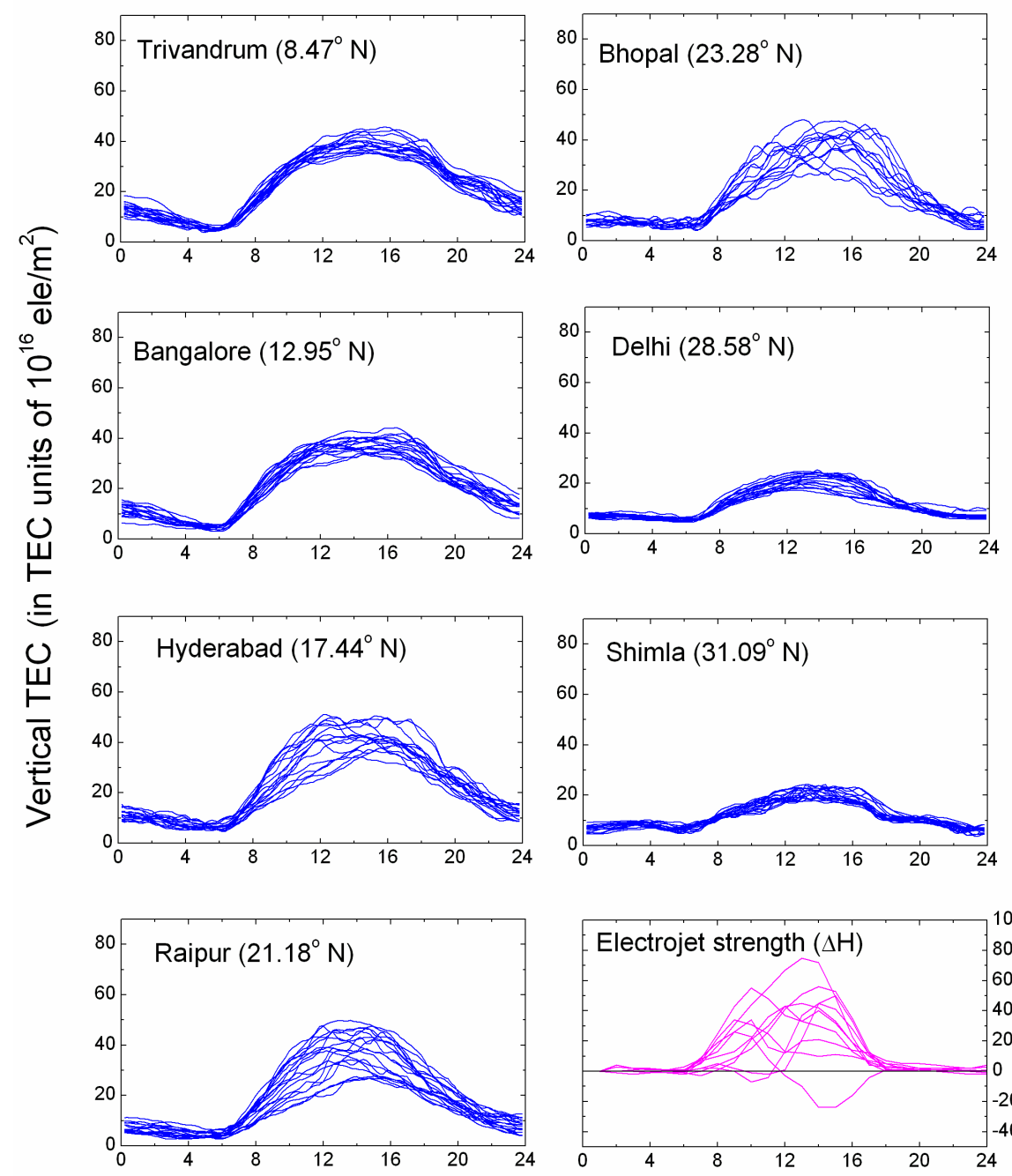

IST (LT)

Fig. 5. Mass plots of the diurnal variation of TEC measured at seven locations situated along a common meridian of $77^{\circ} \mathrm{E}$ longitude for the quiet days in the winter month of December 2004 presented along with the diurnal variations of the corresponding electrojet strength (EEJ) variations.

of the country and the northern crest of the equatorial ionization anomaly lies in the middle of the country, providing a unique opportunity for making studies on the latitudinal variation of some of the important ionospheric phenomena, such as equatorial ionization anomaly (EIA), Equatorial Ionization and Temperature Anomaly (EITA) and the occurrence of intense scintillations. In the following section, a detailed study on the variation of TEC as a function of latitude in the Indian sector, using the simultaneous TEC data from the seven stations chosen along the common meridian of $77^{\circ} \mathrm{E}$ longitude, all the way from the magnetic equator to the anomaly crest and beyond, is carried out and the results are presented. It may be mentioned here that, from isolated and individual measurements of $\mathrm{foF}_{2}$ (from ionosonde) and
TEC (from orbiting, as well as Geostationary satellites) during the past 3 to 4 decades, studies on the latitudinal variation of the electron density in the Indian sector have been carried out (Rastogi et al., 1973, 1975; Iyer et al., 1976; Rama Rao et al., 1977; Klobuchar et al., 1977) and the broad features in the behaviour of the equatorial ionization anomaly are brought out. It is also known that the equatorial ionization anomaly is a result of the so-called fountain effect, which in fact is the consequence of the effect of the equatorial electrojet interaction with the horizontal (N-S) Earth's magnetic field at the equator which gives rise to a lifting of the equatorial plasma to higher altitudes, during most of the daytime hours. This plasma subsequently diffuses along the geomagnetic field lines to either side of the magnetic equator, 


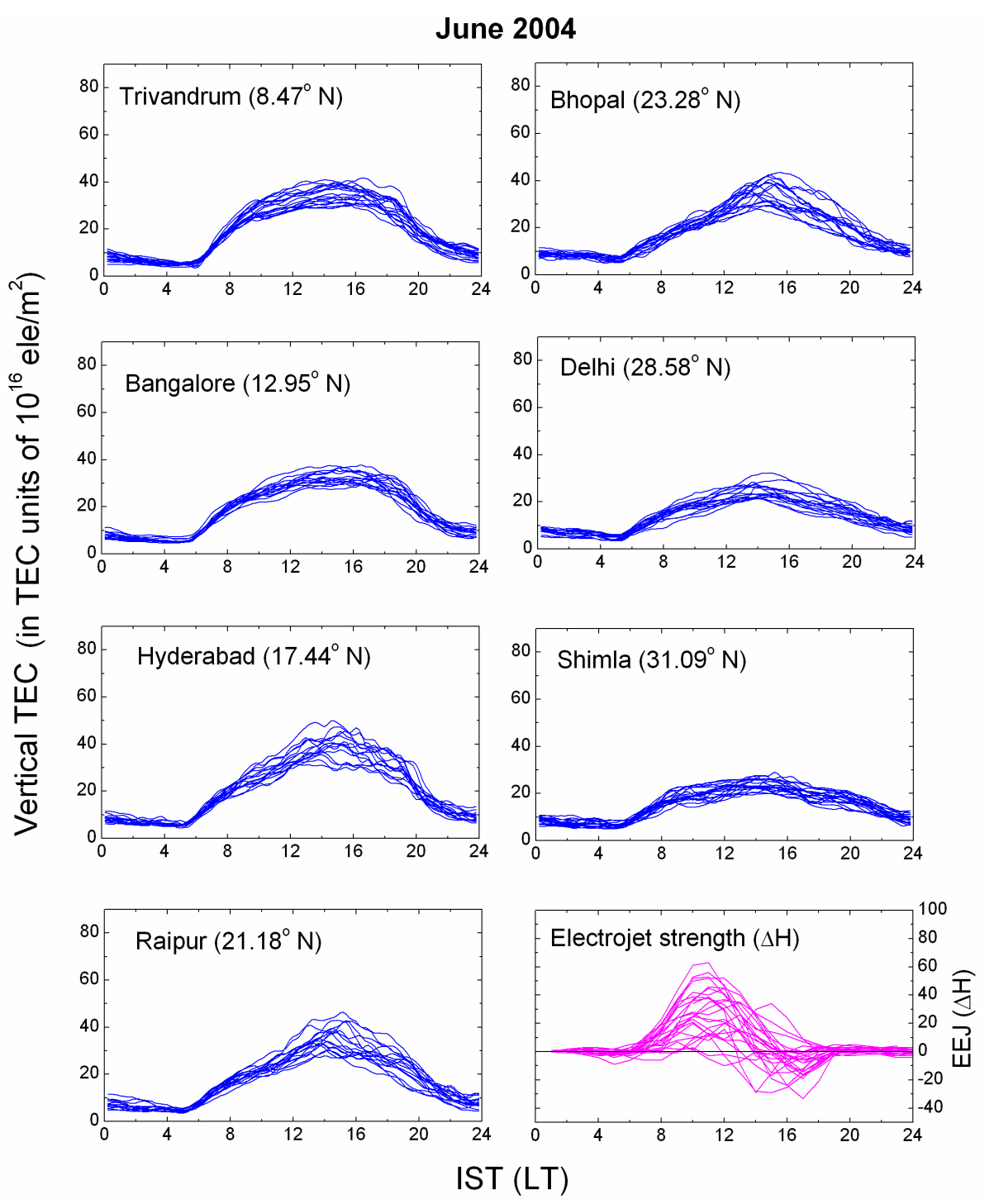

Fig. 6. Mass plots of the diurnal variation of TEC measured at seven locations situated along a common meridian of $77^{\circ} \mathrm{E}$ longitude for the quiet days in the summer month of June 2004, presented along with the diurnal variations of the corresponding electrojet strength (EEJ) variations.

owing to the effects of ambipolar diffusion, gravity and pressure gradients, giving rise to an accumulation of ionization at the F-region altitudes around $\pm 15^{\circ}$ geomagnetic latitudes, resulting in the formation of crests of ionization, while simultaneously depleting the ionization over the magnetic equator. With the availability of continuous and simultaneous TEC data from the Indian GPS network of stations, a systematic study on the latitudinal variation of TEC has been carried out and the results are presented. Because the plasma diffuses along the field lines to latitudes away from the magnetic equator, in the direction of magnetic meridian, the study will become more appropriate if the data are chosen along the same longitude (to avoid the longitudinal differences, if any). Although TEC data is available from all 18 different loca- tions in India, encompassing different longitude and latitude zones, the data from stations that lie along a common longitude which covers the maximum latitude extent of the Indian region, are chosen. Hence, the TEC data from the seven stations thus identified, namely Trivandrum $\left(8.47^{\circ} \mathrm{N}\right)$, Bangalore $\left(12.95^{\circ} \mathrm{N}\right)$, Hyderabad $\left(17.44^{\circ} \mathrm{N}\right)$, Raipur $\left(21.18^{\circ} \mathrm{N}\right)$, Bhopal $\left(23.28^{\circ} \mathrm{N}\right)$, Delhi $\left(28.58^{\circ} \mathrm{N}\right)$ and Shimla $\left(31.09^{\circ} \mathrm{N}\right)$, along the common meridian of $77^{\circ} \mathrm{E}$, are considered and the diurnal variation at each of these stations for all the identified quiet days in each of the 16 months, from March 2004 to February 2005, are prepared and the results discussed.

Typical diurnal variation plots of TEC for three quiet days, namely 23 October, 3 December and 22 June 2004 from all these seven stations are considered for a preliminary 
(a) Trivandrum $\left(8.47^{\circ} \mathrm{N}\right)$

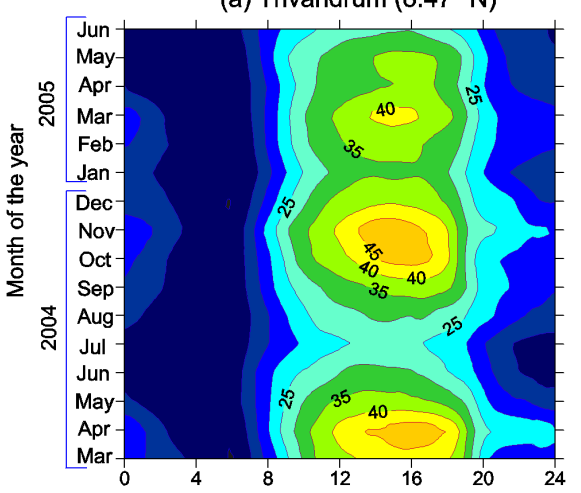

(c) Raipur $\left(21.18^{\circ} \mathrm{N}\right)$

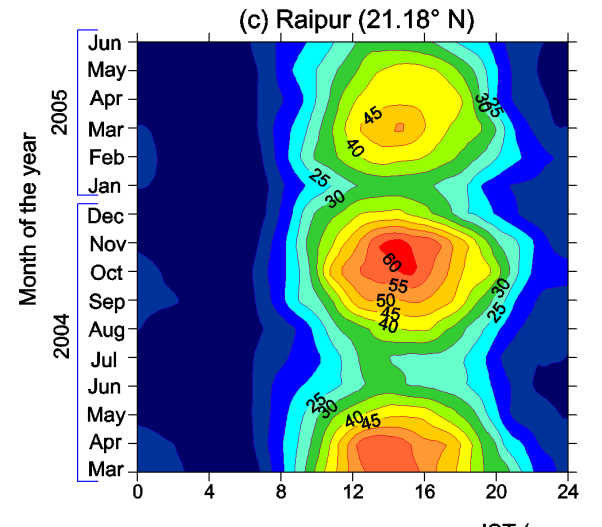

(b) Hyderabad $\left(17.44^{\circ} \mathrm{N}\right)$

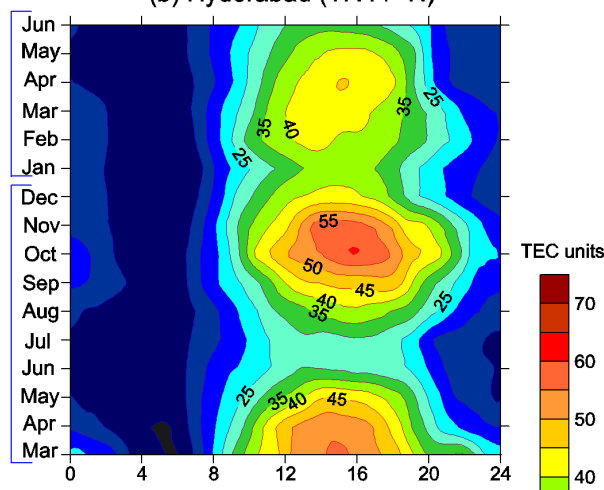

(d) Delhi $\left(28.58^{\circ} \mathrm{N}\right)$

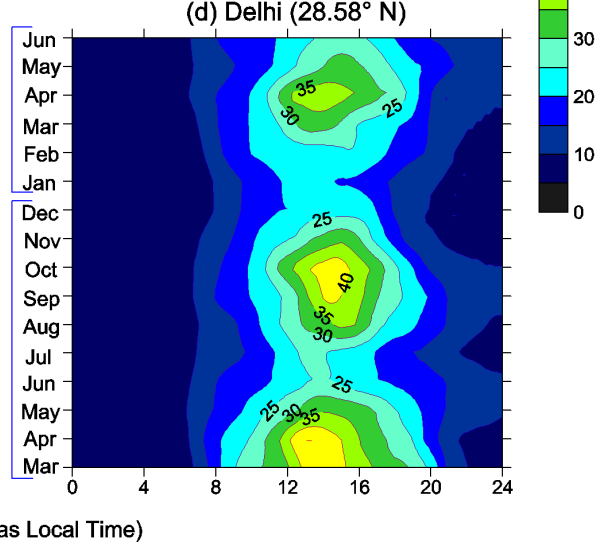

Fig. 7. Contour plots of the monthly average diurnal variation of TEC at (a) an equatorial station Trivandrum $\left(8.47^{\circ} \mathrm{N}\right)$, (b) a sub-tropical station, Hyderabad $\left(17.44^{\circ} \mathrm{N}\right)$, (c) an ionization anomaly crest station, Raipur $\left(21.18^{\circ} \mathrm{N}\right)$, and $(\mathbf{d})$ a station beyond the anomaly crest, Delhi $\left(28.58^{\circ} \mathrm{N}\right)$, during the 16-month period from March 2004 to June 2005, showing the significant feature of clear latitudinal and seasonal variation in TEC with equinoxial maxima.

examination and the corresponding contour plots are presented in Figs. 8a, b, and c, respectively, along with the variation of the corresponding EEJ strength. It may be seen from these figures that the day maximum value of the total electron content (TEC) increases from the equator to the anomaly crest region (Raipur/Bhopal) and decreases significantly at stations Delhi and Shimla, which lie outside the anomaly crest region. It may also be seen from these figures that the magnitude of the TEC on the equinoxial day (23 October 2004 ) is maximum followed by the winter day (3 December 2004) and is minimum during the summer day of 22 June 2004. The maximum electron content of 70 TEC units occurs during the local time of 13:00 to 15:00 $\mathrm{h}$ and maximizes around the geographic latitudes of $21^{\circ}$ to $24^{\circ} \mathrm{N}$, i.e. around Raipur and Bhopal on the equinoxial day of 23 October 2004. On this day, the equatorial electrojet strength $(\Delta \mathrm{H})$, plotted as a function of local time, also shows a broad peak with a maximum $\Delta \mathrm{H}$ value of 62 and an integrated EEJ strength $(\Sigma \Delta \mathrm{H})$ of 442 , as may be seen from the plot presented under the same Fig. 8a, indicating that the higher the electrojet strength, the higher the altitude to which the plasma is lifted at the equator and the farther the location is of the crest of the equatorial ionization anomaly. From Fig. 8b, i.e. 3 December, it may be seen that the maximum electron density of 60 TEC units occurs around 16:00 h local time at a geographic latitude of about $17^{\circ} \mathrm{N}$ (i.e. around Hyderabad). The corresponding equatorial electrojet on this day shows a peak value of 55 with an integrated EEJ strength of 326, suggesting that both the magnitude and the latitude of the location of the anomaly crest decreases with the decrease in the electrojet strength. On 22 June 2004, which represents a typical summer day, (which is also a quiet day with $\mathrm{Ap}=2$ ) the contour diagram of TEC, drawn as a function of local time and latitude, presented in Fig. 8c, did not show the formation of the crest of equatorial ionization anomaly, but, on the other hand, it showed that the peak TEC value reduces to 30 TEC units and maximizes between 12:00 to 16:00 LT, closer to the equator. On this day, typically the electrojet showed a maximum value of 23 with an integrated strength of EEJ of 4 , clearly indicating that the EEJ plays a major role, i.e. the larger the electrojet strength, the greater the strength of the anomaly crest and the farther is its location and vice-versa.

The broad features in the seasonal variation of the equatorial ionization anomaly in TEC are studied by preparing 
(a) 23rd October 2004
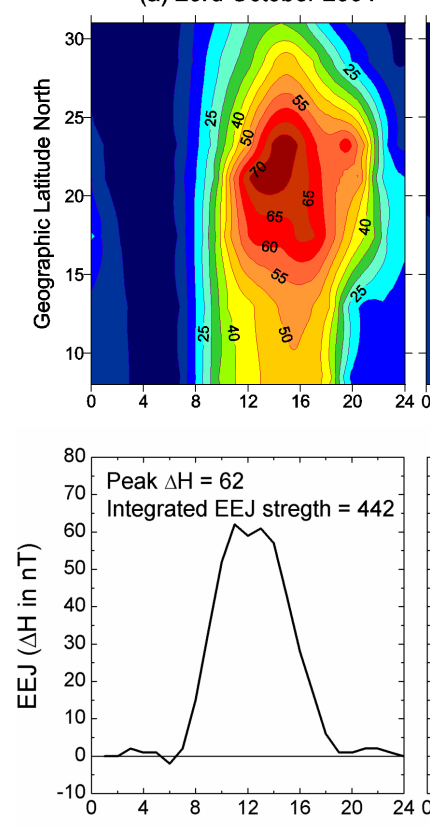

(b) 03rd December 2004

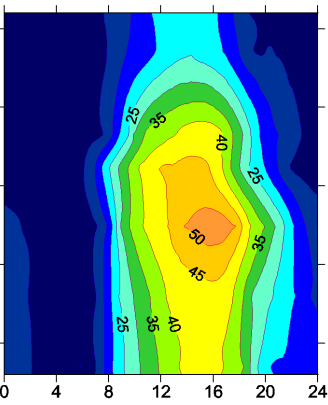

(c) 22nd June 2004
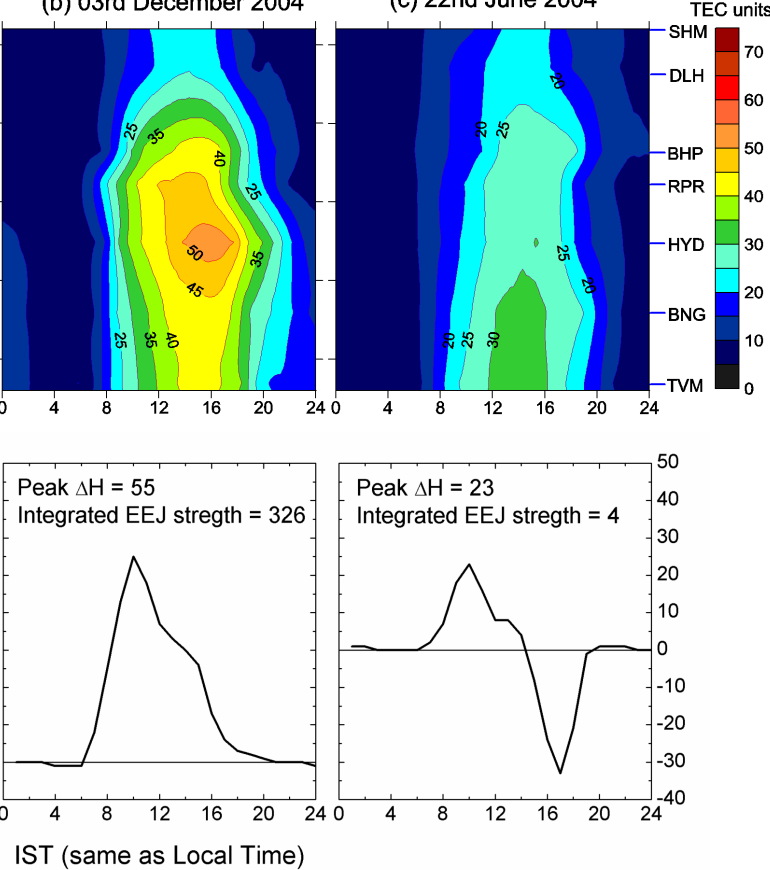

Fig. 8. Typical contour plots of the diurnal variations of TEC, drawn as a function of geographic latitude (seven stations on a common meridian of $77 \mathrm{E}$ longitude) for (a) an equinoxial day, 23 October 2004 (b) a winter day, 3 December 2004 and (c) a summer day, 22 June 2004, along with the corresponding diurnal variations of the equatorial electrojet strengths.

The stations are indicated by TVM - Trivandrum (8.47), BNG - Bangalore (12.95), HYD - Hyderabad (17.44), PRP - Raipur (21.18), BHP - Bhopal (23.28), DLH - Delhi (28.58), SHM - Shimla (31.09).

the monthly average diurnal variation plots of TEC for each day in each of the 12 months, from March 2004 to February 2005 , for all the quiet days at the seven identified stations specified earlier, for further examination. The contour diagrams of TEC, drawn as a function of local time versus latitude, prepared from the monthly mean values of TEC, are presented by season, along with the corresponding average EEJ strengths. Figure 9a shows these variations in TEC for the set of four equinoxial months, i.e. March, April, September and October of 2004, where the TEC maximizes between 12:00 to 16:00 LT. From Fig. 9a it is seen that the crest of the equatorial ionization anomaly broadly lies in the geographic latitude belt of $15^{\circ}$ to $25^{\circ} \mathrm{N}$, with the peak occurring around $20^{\circ}$ to $23^{\circ} \mathrm{N}$ during the equinoxial months. In general, the crest of the equatorial ionization anomaly in the Indian sector maximizes around the latitudes of Raipur $\left(21.18^{\circ} \mathrm{N}\right)$ and Bhopal $\left(23.28^{\circ} \mathrm{N}\right)$, often starting from the latitudes around Waltair $\left(17.7^{\circ} \mathrm{N}\right)$ and Hyderabad $\left(17.44^{\circ} \mathrm{N}\right)$. The average electrojet strengths presented along with this figure for the corresponding equinox months also show higher values of EEJ, justifying the strength and location of the crest of the equatorial ionization anomaly. A similar plot for the months of November, December 2004 and January, February 2005, representing winter months, is presented in Fig. 9b. Here again, similar features are also seen but with a much reduced intensity in the electrojet strength and TEC, as well as in the location of the crest of the anomaly moving equatorward, whereas during the summer months of May, June, July and August 2004, the ionospheric plasma densities are, in general, lower at low latitudes and the formation of the crest of the equatorial ionization anomaly is weak and is almost absent, as may be seen from Fig. 9c. However, the corresponding average electrojet strength is relatively higher compared to those of the winter months. This ambiguity may probably be attributed to the lower ambient electron densities during the summer months, owing to the reduced production rates, as indicated by the reduced $\mathrm{O} / \mathrm{N}_{2}$ ratios (Titheridge, 1974).

\section{Relation between equatorial Ionization Anomaly (EIA) and the Equatorial Electrojet (EEJ)}

The intensity and location of the equatorial ionization anomaly appears to be mainly dependent on the strength and duration of the equatorial electrojet. In the present study the results strongly suggest a positive relation between EIA and the integrated strength of the EEJ. Therefore, it is thought to be worthwhile to examine whether there is any quantitative relation which can be derived from these observed results. Hence, two approaches have been tried, using the values of the IEEJ $(\Sigma \Delta \mathrm{H})$ and the anomaly strength in TEC, and the 
(a) Equinox
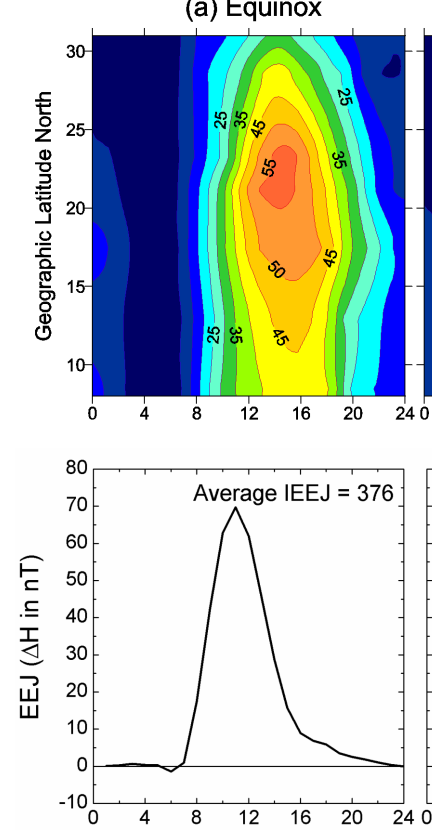

(b) Winter

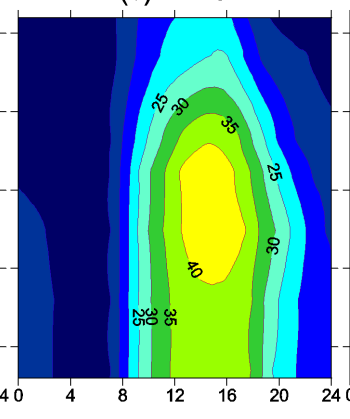

(c) Summer

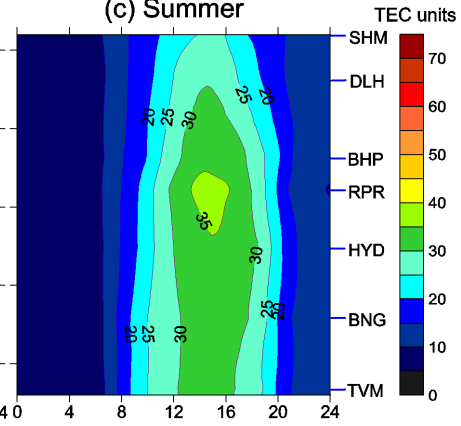

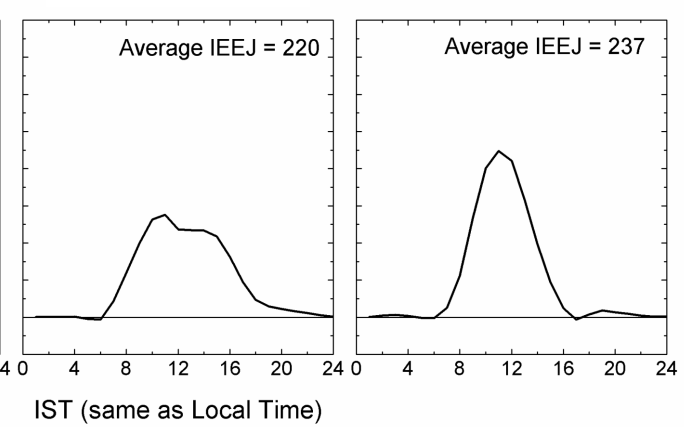

Fig. 9. Contour plots showing the seasonal average diurnal variations as a function of geographic latitude during the quiet days of the three seasons (a) equinox, (b) winter and (c) summer at the seven stations chosen along the common meridian of $77^{\circ} \mathrm{E}$ longitude. In the bottom panel the corresponding average diurnal variations of the integrated equatorial electrojet (IEEJ) strength are presented for comparison.

The stations are indicated by TVM - Trivandrum (8.47), BNG - Bangalore (12.95), HYD - Hyderabad (17.44), PRP - Raipur (21.18), BHP - Bhopal (23.28), DLH - Delhi (28.58), SHM - Shimla (31.09).

IEEJ strength and the crest location, in order to find a relation between the anomaly crest location in latitude and the corresponding Integrated Equatorial Electrojet strength IEEJ $(\Sigma \Delta \mathrm{H})$, and the other to find a similar relation between the peak value of the TEC at the anomaly crest region and the corresponding integrated diurnal IEEJ strength.

In Fig. 10a the latitudinal location is presented of the crest of the equatorial ionization anomaly as a function of the IEEJ strength. It may be seen from this figure that the location in the crest of the EIA varies from a minimum of $17^{\circ} \mathrm{N}$ to a maximum of $25^{\circ} \mathrm{N}$, while the corresponding IEEJ varies from a minimum of $150 \mathrm{nT}$ to a maximum of $650 \mathrm{nT}$ and shows a clear linear relation between them. Similarly, the strength of the EIA (peak TEC value at the crest) as a function of the IEEJ is presented in Fig. 10b. It is also seen from this figure that there exists a similar linear relation showing that the strength of the EIA increases with the increase of the IEEJ strength. Further, it may be noticed from these two figures (Figs. 10a and b) that there is a considerable spread in the points on either side of the regression lines, which may be attributed to the effects of other additional processes and phenomena, such as the day-to-day variation in the neutral winds and local electric fields added to the control of the EEJ on the EIA.

\section{Latitudinal variation in the formation of the northern crest of equatorial ionization anomaly in the Indian region}

The establishment of the network of the 18 GPS receivers under the GAGAN project in the Indian sector has given an unique opportunity for making continuous and simultaneous measurements of TEC, comprehensive information of which is of vital importance in the space weather related applications, such as the Satellite Navigation and Communication Systems. In Fig. 11a the vertical TEC (VTEC) values are presented, measured during the local time of $09: 30 \mathrm{~h}$, from the GPS network of receivers from all 18 stations over the entire country on a typical quiet day of 23 October 2004. It may be seen from this figure that the TEC is in the buildingup stage and shows higher values over the equatorial region compared to the latitudes away from the equator. The colour codes of the dots in the figure indicate the strength of TEC at different locations in India. As the day advances, the electric fields increase, thereby increasing the vertical drifts at the equator and give rise to the movement of the plasma to higher altitudes. Around late afternoon, i.e. at 15:30 LT, on this day the equatorial ionization anomaly is fully developed, as may be seen from Fig. 11b. In this figure the higher TEC values (red dots) are accumulated in the geographic latitude zone of $15^{\circ}$ to $25^{\circ} \mathrm{N}$ (i.e. $5^{\circ}$ to $15^{\circ} \mathrm{N}$ geomagnetic latitudes), 

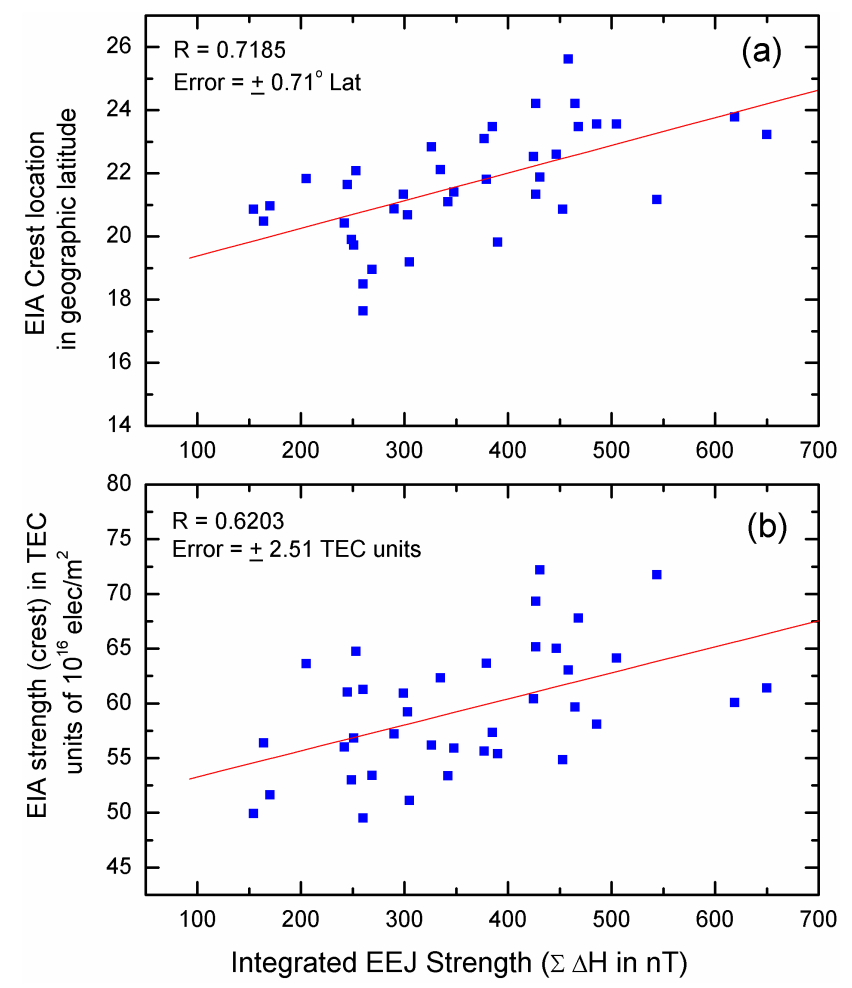

Fig. 10. Plots showing (a) the variation in the geographic latitudinal location of the crest of the equatorial ionization anomaly (EIA) and (b) the variation of the strength of the anomaly crest (in TEC units) as a function of the IEEJ strength $(\Sigma \Delta \mathrm{H}$ in $\mathrm{nT})$.

clearly showing the formation of the EIA in the Indian northern latitudes, as has already been presented earlier using the seven stations of data chosen along the common meridian of $77^{\circ} \mathrm{E}$. Here, this diagram (11a and b) shown, along with the background map of the Indian region, using data from all 18 stations, gives an overall picture of the development of EIA in this part of the globe and will be of interest for the users in anticipating and evaluating the range delays.

\section{Summary}

This paper, for the first time, presents the spatial and temporal variations of the equatorial ionosphere, using the simultaneous measurements of TEC, made with the GPS network of receivers from the equator to the northern Equatorial Ionization Anomaly (EIA) crest region and beyond in the Indian sector, covering a geomagnetic latitude range of $1^{\circ} \mathrm{S}$ to $24^{\circ} \mathrm{N}$. The diurnal, seasonal and latitudinal variations of TEC derived from all the stations are studied for a 16-month period during the low sunspot activity (LSSA) period from March 2004 to June 2005, the results of which are summarized and presented.

The diurnal variation at the EIA region reaches its maximum value between 13:00 and 16:00 LT, whereas near the
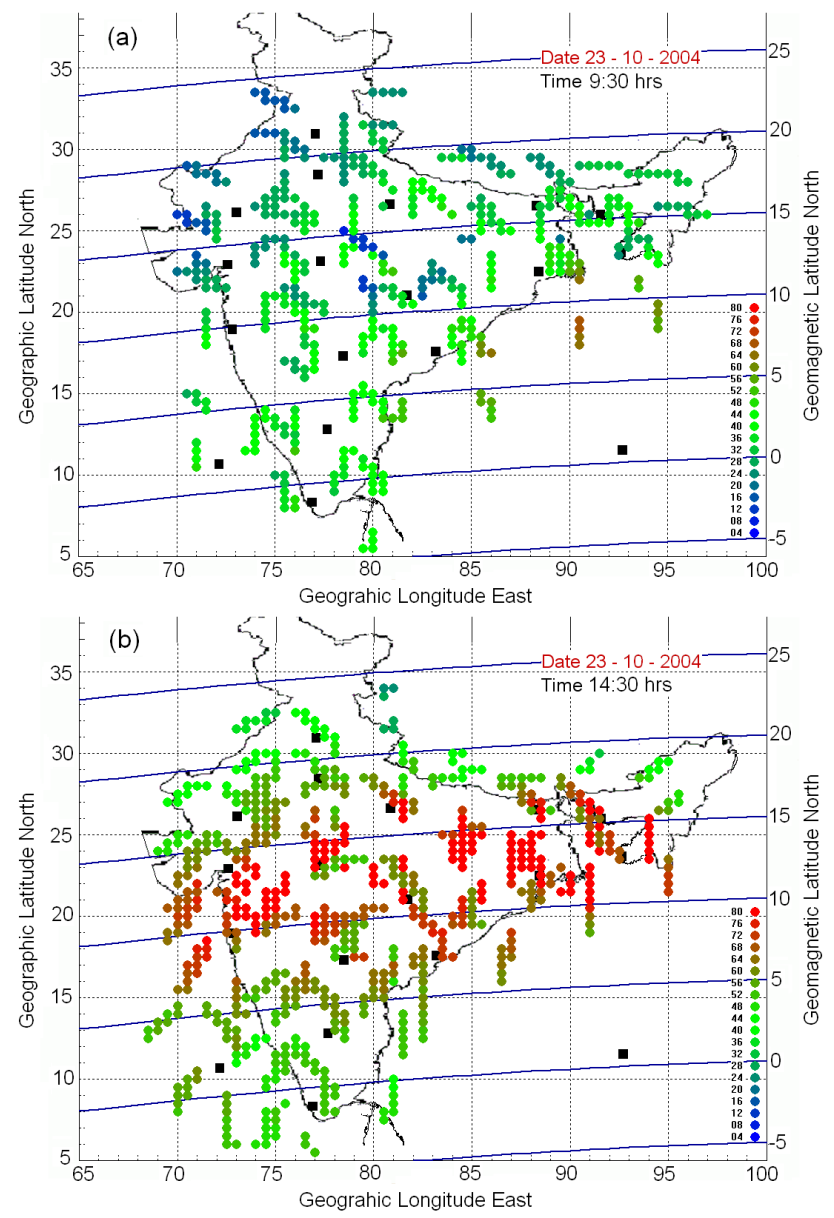

Fig. 11. Variation of TEC over the Indian latitudes. (a) During the building-up stage of TEC (from 09:00 to 10:00 LT) and (b) during the local time (14:00 to $15: 00 \mathrm{~h}$ ) when the EIA is fully developed and confines to 15 to $25^{\circ} \mathrm{N}$ geographic latitudes. The colour codes represent the strengths of TEC.

equator the day maximum is broad and its peak is delayed and occurs around 16:00 LT. Similarly, the day minimum in TEC occurs between 05:00 and 06:00 LT at all stations from the equator to the EIA crest region. However, beyond the crest region an extended day minimum is found to occur which is flat during most of the nighttime hours, i.e. from 22:00 to 06:00 LT, a feature which is similar to that at midlatitudes. The diurnal variation in TEC shows a minimum to maximum variation of about 5 to 50 TEC units at the equator and from 5 to 90 TEC units at the EIA crest region. These TEC values correspond to range delay variations of about 1 to $8 \mathrm{~m}$ at the equator and about 1 to $15 \mathrm{~m}$ at the crest region, at the GPS-L1 frequency of $1.575 \mathrm{GHz}$. These variations in the range delays will certainly increase in high sunspot activity (HSSA) periods. The day-to-day variability in TEC is also significant at all the stations, particularly during daytime hours, with a maximum variation at the EIA crest regions. 
Further, it is noticed that the day-to-day variability in the corresponding EEJ strengths are equally significant in effecting the day-to-day variations in TEC. Also, the location of the EIA crest and its peak value in TEC increases with the increase in the integrated equatorial electrojet (IEEJ) strength.

The monthly average diurnal variations show that the TEC maximizes during the equinox months followed by the winter months, and are lowest during the summer months. The lower values of TEC during the summer months may be attributed to the low ionization densities, due to the reduced production rates (indicated by $\mathrm{O} / \mathrm{N}_{2}$ ratio), owing to the increased scale height of $\mathrm{N}_{2}$ (Titheridge, 1974).

Acknowledgements. The authors wish to thank K. Bandhopadhyay and M. R. Sivaraman of the Space Application Centre (SAC), Ahmedabad for providing TEC and S4-index data and A. Bhattacharya of Indian Institute of Geomagnetism (IIG), Mumbai for providing the magnetogram data. One of the authors (SGK) is grateful to Council of Scientific and Industrial Research (CSIR) and Space Physics Laboratory (SPL - VSSC - ISRO) for providing him with fellowships during the progress of this research work.

Topical Editor M. Pinnock thanks M. Materassi and P. Doherti for their help in evaluating this paper.

\section{References}

Ackroyd, N. and Lorimer, R.: A GPS User's Guide, Lloyd's of London Press, 1990.

Chandra, H. and Rastogi, R. G.: Geomagnetic storm effects on Ionospheric drifts and the equatorial E over the magnetic equator, Indian Journal of Radio and Space Physics, 3, 332-336, 1974.

Coco, D.: GPS - Satellites of Opportunity for Ionospheric Monitoring, GPS World, 47, 1991.

Dasgupta, A. and Basu, A.: Investigation of ionospheric electron content in the equatorial region as obtained by orbiting beacon satellites, Ann. Geophys., 29, 409-419, 1973, http://www.ann-geophys.net/29/409/1973/.

Davies, K. and Hartmann, G. K.: Studying the ionosphere with Global Positioning System, Radio Sci., 32, 1695-1703, 1997.

Davies, K., Donnelly, R. F., Grubb, R. N., and Rama Rao, P. V. S.: ATS-6 satellite radio beacon measurements at Ootacamund, India, Radio Sci., 14, 85-95, 1979.

Davies, K.: Recent progress in satellite radio beacon studies with particular emphasis on the ATS-6 Radio beacon experiment, Space Sci. Rev., 25, 357-430, 1980.

Hocke, K. and Pavelyev, A. G.: General aspect of GPS data use for atmospheric science, Adv. Space Res., 27, 1313-1320, 2001.

Iyer, K. N., Deshpande, M. R., and Rastogi, R. G.: The equatorial anomaly in ionospheric total electron content and the equatorial electrojet current strength, Proc. of Indian Academy of Science, 84, 129-138, 1976.

Kane, R. P.: Irregular variations in the global distribution of total electron content, Radio Sci., 15, 837-842, 1980.

Kane, R. P.: Irregular variations in the global distribution of total electron content, Radio Sci., 15(4), 837-842, 1980.
Klobuchar, J. A., Iyer, K. N., Vats, H. O., and Rastogi, R. G.: A numerical model of equatorial and low latitude total electron content for use by satellite tracking systems for ionospheric corrections, Indian Journal of Radio and Space Physics, 6, 159-164, 1977.

Klobuchar, J. A.: Ionospheric Effects on GPS, in: Global Positioning System: Theory and Applications, Vol 2, edited by: Parkinson, B. W. and Spilker, J. J., Progress in Astronautics and Aeronautics, 164, p. 485, 1996.

Langley, R., Fedrizzi, M., Paula, E., Santos, M., and Komjathy, A.: Mapping the low latitude Ionosphere with GPS, GPS World, 13(2), 41-46, 2002.

Mannucci, A. J., Wilson, B. D., and Edwards, C. D.: A new method for monitoring the earth's ionospheric total electron content using the GPS global network, Proc. of ION GPS-93, Inst of Navigation, 1323-1332, 1993.

Mendillo, M., Lynch, F. X., and Klobuchar, J. A.: Solar Terrestrial Predictions, vol. 4, edited by: Donneylly, R. F., Space Environment Lab, Boulder, Colorado, USA, C1-C14, 1980.

Modi, R. P. and Iyer, K. N.: IEC and slab thickness near the peak of equatorial anomaly during sunspot maximum and minimum, Indian Journal of Radio and Space Physics, 18, 23-26, 1989.

Rama Rao, P. V. S., Gopi Krishna, S., Niranjan, K., and Prasad, D. S. V. V. D.: Study of Spatial and temporal characteristics of Lband scintillations over the Indian low latitude region and their possible effects on GPS navigation, Ann. Geophys., 24, 15671580, 2006, http://www.ann-geophys.net/24/1567/2006/.

Rama Rao, P. V. S., Srirama Rao, M., and Satyam, M.: Diurnal and seasonal trends in TEC values observed at Waltair, Indian Journal of Radio \& Space Physics, 6, 233-235, 1977.

Rastogi, R. G. and Sharma, R. P.: Ionospheric electron content at Ahmedabad (near the crest of equatorial anomaly) by using beacon satellite transmissions during half a solar cycle, Planet. Space Sci., 19, 1505-1517, 1971.

Rastogi, R. G., Iyer, K. N., and Bhattacharyya, J. C.: Total electron content of the ionosphere over the magnetic equator, Current Science, 44, 531-533, 1975.

Rastogi, R. G., Sharma, R. P., and Shodan, V.: Total electron content of the equatorial ionosphere, Planet. Space Sci., 21, 713-720, 1973.

Soicher, H. and Gorman, F. J.: At middle \& high latitudes, soicher and Gorman observed day to day variability is less than $25 \%$ irrespective of location, Proceedings of COSPAR Satellite Beacon Symposium, Warsaw, Poland, 91, 1980.

Sonnenberg, S.: Radio and Electronic Navigation, Chapter 7, Butterworth and Co, 6th Edition, 1988.

Titheridge, J. E.: Changes in atmospheric composition inferred from ionospheric production rates, J. Atmos. Terr. Phys., 36, 1249-1257, 1974.

Van Dierendonck, A. J., Fenton, P., and Klobuchar, J.: Commercial ionospheric scintillation monitoring receiver development and test results, Proceedings of the Institute of Navigation's 52nd Annual Technical Meeting, Cambridge, MA, 573-582, 1996.

Wanninger, L.: Effects of the Equatorial Ionosphere on GPS, GPS World, p. 48, 1993. 